\title{
Atenção concentrada e memória operacional em professores de escola pública e privada
}

\author{
Focused attention and operational memory in public and private school teachers
}

\author{
Nelsione Carla Gonçalves ${ }^{[a]}$, Regina Yoko Nomiyama Lima ${ }^{[b]}$, Leandro Kruszielski[c], \\ Plínio Marco de Tonid]
}

\footnotetext{
${ }^{[a]}$ Faculdade Dom Bosco, Curitiba, PR - Brasil, e-mail: nelsioneg@ hotmail.com

${ }^{[b]}$ Faculdade Dom Bosco, Curitiba, PR - Brasil, e-mail: lima_regina@ hotmail.com

${ }^{[c]}$ Universidade Federal do Paraná e Universidade Tuiuti do Paraná, Curitiba, PR - Brasil, e-mail: leandro.psi@gmail.com

${ }^{[\mathrm{d}]}$ Universidade Estadual do CentroOeste, Irati-PR - Brasil, e-mail: pliniomarco@yahoo.com.br
}

Recebido: 09/06/2012 Received: 06/09/2012

Aprovado: 04/10/2012 Approved: 10/04/2012

\section{Resumo}

As funções executivas são alvo de muitas pesquisas no Brasil e estão relacionadas à capacidade do sujeito em realizar ações voluntárias, planejadas e organizadas. Considerando essa perspectiva, o objetivo desta pesquisa foi investigar as funções cognitivas de memória operacional, planejamento e atenção concentrada em 65 professores do ensino fundamental, sendo 35 de escola particular e trinta de escola pública, ambas em Curitiba. Os instrumentos utilizados para a coleta dos dados foram a Figura Complexa de Rey e o teste de Atenção Concentrada (AC). Verificou-se uma correlação positiva entre a idade dos participantes e o seu nível de erro no teste AC. Notou-se uma diferença estatística significativa entre os dois grupos no tipo de cópia. Considera-se que o planejamento é importante para os docentes, pois todos precisam elaborar, ordenar e preparar os conteúdos a serem ministrados, organizar o tempo de aula e também do ano letivo. Por meio do teste $t$ de Student observou-se uma diferença significativa entre as variáveis, cópia e memória da Figura de Rey, e entre as variáveis, acerto e erro do teste AC. Levantaram-se várias hipóteses para tentar explicar este panorama, mas são necessárias novas pesquisas para comprová-las.

Palavras-chave: Cognição, Memória. Atenção. Planejamento. Professores.

Psicol. Argum. 2014 out./dez., 32(79), $91-98$ 
Complex Figure, and between variables and error adjustment of the AC test. Several hypotheses were formulated in order to explain this scenario, but more researches are needed to prove them.

Keywords: Ethology. Laterality. Phylogenesis.

\section{Introdução}

As funções executivas são alvo de muitas pesquisas no Brasil. De acordo com Capovilla, Assef e Cozza (2007), a Neuropsicologia amplia as investigações em torno do córtex pré-frontal e das funções executivas. Relacionada a essas funções está a capacidade do sujeito de desejar realizar ações voluntárias, independentes, auto-organizadas e orientadas para metas específicas. Compreendem então um aspecto mais complexo da cognição que envolve seleção de informação, planejamento, monitoramento e flexibilidade cognitiva.

Nessa perspectiva, aborda-se a cognição em professores considerando as funções executivas, o pré-frontal, a memória de curto prazo e a atenção concentrada. Sendo assim, o objetivo desta pesquisa é investigar as funções cognitivas de memória operacional, planejamento e atenção concentrada em professores do ensino fundamental.

Sabe-se que a atenção e a memória fazem parte da vida diária do professor e são necessárias sempre que está envolvido em alguma atividade e queira um bom aproveitamento e qualidade do trabalho. Por exemplo, ao corrigir uma prova, as funções executivas desse profissional devem se focar nas respostas do aluno.

Entretanto, diversos autores realizam estudos sobre as funções executivas. Neste sentido, Goldberg (2002) afirma que o córtex pré-frontal é o maestro das estruturas cerebrais ao se referir ao funcionamento harmonioso, ao papel de liderança do córtex frontal e também à conectividade única dos lobos frontais com todas as outras estruturas cerebrais.

A função do córtex pré-frontal é manter um equilíbrio dinâmico entre a autonomia das partes do organismo controlado. Ele deve saber quando intervir e quando deixar as partes do organismo subordinadas tomarem suas próprias iniciativas. É um papel muito difícil de definir, porém decisivo, pois um pequeno lapso no pré-frontal pode acarretar um desastre no funcionamento do cérebro (Goldberg, 2002).
Os lobos frontais têm a função de dirigir a ação, mais especificamente, pelo córtex pré-frontal. $\mathrm{Na}$ história da evolução do homem, o córtex pré-frontal apareceu tardiamente; entre os componentes do cérebro, o homem é o animal que tem os lobos frontais mais desenvolvidos. Como Ratey (2002) afirma, "os seres humanos possuem os maiores e mais desenvolvidos lobos frontais de todos os animais, eles são considerados 'o órgão da civilização' ou 'a sede da inteligência abstrata” (p. 341). Ainda, o córtex pré-frontal desempenha um papel importante na formação de objetivos e no planejamento de estratégias de ação. Ele seleciona as habilidades cognitivas necessárias para a realização dos planos, coordena essas habilidades e também é responsável pela avaliação do sucesso ou do fracasso das ações em relação aos objetivos.

Os lobos frontais relacionam-se com as funções executivas, que se referem "às habilidades cognitivas envolvidas no planejamento, iniciação, seguimento e monitoramento de comportamentos complexos dirigidos a um fim" (Hamdan \& Pereira, 2009, p. 386). Há ainda uma ampla variedade de funções cognitivas implicadas sob a denominação de funções executivas, como a concentração, seletividade de estímulos, capacidade de abstração, flexibilidade de controle mental e autocontrole (Hamdan \& Pereira, 2009).

Em qualquer tarefa ou atividade desempenhada pelo ser humano é necessário que se focalize a atenção concentrada para facilitar o processo ou para promover o bom aproveitamento da qualidade do trabalho. Frequentemente, a atenção se confunde com outras funções mentais, tais como concentração, alerta, despertar, vigilância e observação (Cambraia, 2003).

Para Luria (1991), atenção é "a seleção da informação necessária, o asseguramento dos programas seletivos de ação e a manutenção de um controle permanente sobre elas" (p.1). De acordo com o autor, a atenção tem caráter seletivo e se manifesta na percepção, nos processos motores e no pensamento. Sem a seletividade, a quantidade de informações seria tão desorganizada e grande que se tornaria 
impossível qualquer atividade. Em todos os tipos de atividade consciente há esse processo de seleção do objeto da atenção, e ao mesmo tempo, há um pano de fundo, que pode, a qualquer momento, tornar-se centro da atenção, transformando-se em processo dominante.

Luria (1991) afirma que existem dois tipos básicos de atenção: o arbitrário e o involuntário. A atenção involuntária se dá nos casos em que um estímulo forte, algo novo, interessante ou necessário chama a atenção. "Os mecanismos da atenção involuntária são comuns no homem e no animal" (Luria, 1991, p. 22). Contudo, a atenção arbitrária é inerente ao ser humano, pois, como Luria (1991) explica, "o principal fator indicador da existência de um tipo especial da atenção no homem, não inerente aos animais, consiste em que o homem pode concentrar arbitrariamente a atenção ora em um ora em outro objeto, inclusive nos casos em que nada muda na situação que o cerca" (p. 23).

Eysenck e Keane (2007), por sua vez, diferenciam a atenção focalizada ou seletiva e a atenção dividida. A primeira acontece quando são apresentados dois ou mais estímulos, e a pessoa é instruída a responder a apenas um deles. Já na segunda, apresentam-se pelo menos dois estímulos e os participantes do estudo são instruídos a responder a todos eles. Esse tipo de estudo fornece "informações úteis sobre as limitações de processamento de um indivíduo, e apontam algo sobre os mecanismos da atenção e sua capacidade" (Eysenck \& Keane, 2007, p. 142).

Os autores apontam três limitações importantes para as pesquisas sobre a atenção. A primeira aborda a questão do ambiente externo e interno. A maior parte das pesquisas, de acordo com Eysenck e Keane (2007, p. 142), se realiza em relação ao ambiente externo, por ser "mais fácil identificar e controlar os estímulos ambientais do que os determinantes internos da atenção". 0 segundo fator apontado pelos autores é que na vida real a atenção se volta para os objetivos, e na pesquisa, os participantes observam a instrução do experimentador e não são movidos por seus estados motivacionais. Em terceiro lugar, a realidade da pesquisa sobre atenção geralmente se apresenta em 2-D enquanto que no mundo real os objetos se mostram tridimensionalmente.

0 estudo da memória, de acordo com Luria (1991), advém do século passado, com Ebbinghaus, que propôs um método pelo qual seria possível descrever as leis da memória pura. Estudava-se, então, a atividade de conservação dos vestígios na memória e o seu processo de extinção seguindo o procedimento de decorar sílabas sem sentido. Kraepelin acompanhou esse trabalho (processo de memorização dos doentes com alterações psíquicas), assim como Müller (leis básicas de reforço de reprodução dos vestígios da memória humana).

Seguiram-se inúmeros outros grandes pesquisadores, como Thorndike, Pavlov, Watson, Skinner, além de Vigotski e seus discípulos Leontiev e Zamkov, a quem se deve o primeiro estudo sistemático das formas superiores de memória.

No entanto, apesar do sucesso das pesquisas, os processos fisiológicos ainda eram desconhecidos até a tentativa de discriminar áreas do cérebro essenciais para a conservação de informações e mecanismos neurológicos que servem de base para a memorização e ao esquecimento.

Ainda segundo Luria (1991), há neurônios que não têm caráter específico-modal e reagem somente à mudança da excitação. Desta forma, fundamenta-se a teoria de que o hipocampo e as formações a ele relacionadas desempenham papel especial na fixação e conservação de informações. Compreendemse então os distúrbios graves de memória decorrentes de afecções bilaterais do hipocampo, como a Síndrome de Korsakoff, que apresenta um quadro de impossibilidade de fixar as excitações que chegam.

Contudo, a memória não se limita à participação de apenas algumas áreas do cérebro. É um processo complexo que envolve diferentes sistemas cerebrais que realizam a atividade juntos, embora o funcionamento normal do chamado círculo hipocampo-tálamo-mamilar (Circuito de Papez) tenha a função essencial para a capacidade de registrar e fixar.

Para Sternberg (2000), a aquisição dessas estruturas cerebrais é recente e se considera importante saber que a estimulação repetida de circuitos neuronais tende a reforçar a probabilidade de disparo, ou seja, há uma modificação fisiológica nos dendritos do neurônio receptor, fazendo com que este se posicione novamente no limiar do disparo.

Alguns neurotransmissores interferem no armazenamento da memória. Tanto a serotonina quanto a acetilcolina, assim como a noradrenalina, intensificam a transmissão neuronal associada à memória. Como ilustração, os pacientes com Alzheimer mostram grande perda do tecido cerebral que secreta a acetilcolina, isto é, há uma baixa concentração

Psicol. Argum. 2014 out./dez., 32(79), 91-98 
deste neurotransmissor nessas vítimas. No caso da Síndrome de Korsakoff anteriormente citada, é uma consequência do abuso grave ou prolongado de álcool, que perturba a atividade da serotonina.

Por outro lado, há fatores fisiológicos, como alguns hormônios de ocorrência natural, que incitam a maior disponibilidade de glicose no cérebro, intensificando a função da memória. Isso está relacionado, geralmente, a fatos estimulantes como realizações e experiências inéditas, crises ou momentos de decisões importantes.

Izquierdo (2002), por sua vez, concebe a memória como "aquisição, formação, conservação e evocação de informações" (p. 9). Para ele, a pessoa só se lembra daquilo que foi gravado ou aprendido. Acredita que se pode classificar as memórias de acordo com a sua função (de trabalho), tempo de duração (curta, longa e remota) e conteúdo (declarativas e procedurais).

A memória de curta duração é aquela que dura poucas horas e tem um processo que envolve mecanismos próprios e distintos da memória de longa duração, embora demandem das mesmas estruturas nervosas. De acordo com Izquierdo (2002), a memória de curta duração "estende-se desde os primeiros segundos ou minutos seguintes ao aprendizado até 3-6 horas" (p. 51). Sua função é de manter o indivíduo em condições de responder, por meio de uma repetição da memória principal, enquanto esta ainda não esteja consolidada.

Assim como Luria, Izquierdo (2002) também defende que a região hipocampal é o principal protagonista da formação de memórias. Acrescenta ainda que esse mesmo sistema hipocampal, após intensa atividade intelectual, pode ser saturada, intervindo no seu bom desempenho e, consequentemente, comprometendo a memória e a capacidade de apreender novas tarefas durante minutos ou horas.

Entre as memórias sensoriais (breve, com duração de poucos segundos), pode-se identificar a icônica (imagens) e a ecoica (auditiva). As memórias que não são retidas também não parecem ser armazenadas em um depósito permanente. Logo, existe um sistema de armazenamento intermediário, que será denominado de memória de curto prazo (MCP). 0 limite aproximado de armazenamento da MCP é de 11 dígitos. Já a memória de longo prazo (MLP) é capaz de guardar grandes quantidades de informações e por um período longo de tempo (horas, dias, semanas ou anos).
A memória falha quando, segundo Izquierdo (2002), as sinapses responsáveis se encontram em um número desfavorável, estão inibidas ou alteradas. Desde o nascimento até a idade adulta ocorre a diminuição gradativa do número de neurônios.

No Brasil, não se encontrou nenhum estudo que relacionasse esses constructos em profissionais da área da educação. Nos indexadores Scielo, Medline, Lilac e Pepsic, com as palavras chave professor, atenção e memória, em português, até junho de 2011, não se obteve resultado positivo. Considerando tais fatores, é primordial a pesquisa sobre a atenção e a memória em professores.

\section{Método}

\section{Participantes}

A amostra se constitui de 65 professores de ensino fundamental, distribuídos em duas escolas de Curitiba, uma particular, com 35 participantes, e uma pública, com trinta. Deste total, seis professores são do sexo masculino e 59 do sexo feminino. A faixa etária se apresenta entre 22 e 62 anos. A maioria dos participantes da pesquisa tem entre 34 a 39 anos de idade. A média de idade dos participantes é de 36 anos. 0 nível de atuação dos professores na escola particular varia de educação infantil ao ensino médio. Já na escola pública todos atuam do primeiro ao quinto ano do ensino fundamental.

\section{Instrumentos}

Os instrumentos de coleta de dados empregados foram a Figura Complexa de Rey (Rey, 2010) e o teste de Atenção Concentrada (Cambraia, 2003).

Utiliza-se a Figura Complexa de Rey em pesquisas neuropsicológicas para medir a construção viso-espacial e a memória não verbal. Permite, assim, estudar o atraso no desenvolvimento mental e também a perturbação na estruturação espacial. De acordo com Jamus e Mader (2005), o teste da Figura Complexa de Rey é um dos mais empregados no campo das Neurociências, pois permite avaliar a organização viso-espacial, o planejamento e o desenvolvimento de estratégias, bem como a memória. Foi desenvolvido por André Rey, em 1941 e padronizado por Osterrieth, em 1944. 
A Figura Complexa de Rey consiste em uma figura geométrica complexa composta por um retângulo grande, bissetores horizontais e verticais, duas diagonais, e detalhes geométricos adicionais interna e externamente ao retângulo grande. A aplicação é simples, mas a avaliação e interpretação é um tanto complexa, pois, em um primeiro momento, o indivíduo será solicitado para copiar a figura e, posteriormente, sem aviso prévio, a reproduzi-la de memória. Desta forma, avaliam-se tanto a memória imediata quanto a tardia. Alguns autores preferem a utilização de vários lápis de cor que são apresentados em uma sequência. 0 objetivo é observar a sucessão dos elementos copiados e avaliar a capacidade de desenvolvimento das estratégias.

0 teste de Atenção Concentrada (AC) objetiva mensurar a atenção, a concentração, a rapidez e a exatidão. É de autoria de Suzy Cambraia, em 1967, que passou por várias revisões, sendo a última em 2003.

A atenção concentrada, de acordo com Cambraia, se define como

a capacidade de selecionar uma fonte de informação (estímulo do meio ambiente ou do mundo interior) entre todas as que estão disponíveis em um determinado momento e conseguir dirigir sua atenção (manter o foco) para este estímulo ou tarefa a ser realizada no decorrer do tempo (Cambraia, 2003, p. 16).

Para se chegar ao modelo atual do teste AC realizaram-se estudos pilotos, inclusive com relação aos símbolos abstratos, a fim de selecionar quais eram mais adequados para o instrumento, chegando-se finalmente ao formato do triângulo. $\mathrm{O}$ teste consiste em uma folha com 21 linhas com símbolos abstratos para marcar no tempo de 5 minutos. Esses símbolos foram dispostos de forma aleatória nas linhas, sempre contendo sete marcações por linhas. A contagem de pontos se faz contando o total de erros, acertos e omissões geradas pelas respostas e deve-se recorrer a uma tabela para verificar o percentil, conforme a região e escolaridade. A aplicação do teste pode ser feita individual ou coletivamente.

\section{Procedimentos}

Para a coleta de dados, realizou-se, inicialmente, um contato com a coordenação da escola a fim de apresentar os objetivos do estudo e, posteriormente, obteve-se a sua autorização e apoio, assim como dos professores para a aplicação do instrumento de pesquisa.

Após a assinatura do Termo de Consentimento Livre e Esclarecido, a coleta se deu de forma individual, no tempo aproximado de 10 minutos por participante.

Também se buscaram dados sócio-demográficos como idade, gênero, escolaridade, carga horária de trabalho, disciplina e períodos para o qual lecionava e o tempo de atuação na área docente.

\section{Resultados e discussão}

Com os resultados obtidos entre os 65 professores pesquisados, realizou-se uma análise descritiva e também inferencial. Ao analisar inferencialmente os dados, verificou-se uma correlação positiva entre a idade dos participantes e seu nível de erro no teste $\mathrm{AC}(\mathrm{r}=0,26 \mathrm{p}=0,04)$. Outra variável que obteve correlação com a idade, neste caso correlação negativa, foi o teste Figura de Rey, no quesito memória $(r=-0,24 ; p=0,06)$. Isso significa que quanto maior a idade, maior a probabilidade de erros no teste $\mathrm{AC}$; por outro lado, quanto menor a idade, melhor a memória no teste da Figura de Rey.

Apesar dessas correlações serem fracas, Rueda e Castro (2010) comprovam que os idosos apresentam um desempenho pior que adultos e adolescentes em pesquisas sobre a atenção. As correlações obtidas não são determinantes, porém, em uma amostra maior, os dados poderiam ser mais significativos.

Observou-se também uma correlação positiva entre as variáveis, cópia e memória da Figura de Rey $(\mathrm{r}=0,39 ; \mathrm{p}=0,001)$ e entre acertos do AC e memória da Figura de Rey $(r=0,42 ; p=0,001)$. Além disso, se verificou uma correlação negativa entre cópia da Figura de Rey e erros do AC ( $r=-0,28 ; p=-0,02)$. Isso significa-que os professores com maior tendência em acertar as respostas do AC, também se sairão melhor no teste Figura de Rey na questão da memória. Os que apresentam melhor desempenho na cópia têm possivelmente, um melhor resultado na memória. Em contrapartida, os profissionais que têm mais erros no AC provavelmente obterão piores resultados na cópia da Figura de Rey.

De acordo com Capovilla (2006), apesar de tradicionalmente as funções executivas serem "estudadas pela neuropsicologia como um constructo unitário,

Psicol. Argum. 2014 out./dez., 32(79), 91-98 
pesquisas recentes têm apontado a necessidade desmembrá-las em componentes como memória de trabalho, atenção seletiva, controle inibitório, flexibilidade e planejamento" (p. 239). As funções executivas estão interligadas - memória e atenção apesar de constituírem constructos independentes.

Conforme Gazzaniga e Heatherton (2005), a atenção tem caráter seletivo, escolhendo os estímulos sensoriais que o cérebro deve descartar ou transmitir para níveis superiores. Está presente em todas as atividades conscientes, como um pano de fundo. Por outro lado, os autores entendem a memória como uma capacidade do sistema nervoso de adquirir e reter habilidades ou conhecimentos utilizáveis, para que o organismo se beneficie da experiência. Nesse sentido, existem fatores fisiológicos, como alguns hormônios, que podem intensificar a função da memória.

O tipo de cópia da Figura Complexa de Rey foi uma das principais diferenças encontradas entre as duas escolas. Os tipos de cópia são classificados do mais ao menos racional, fundamentados nos hábitos intelectuais, na rapidez e na precisão da cópia. 0 tipo I se dá quando o sujeito começa a cópia por uma armação geral, e a partir dela constrói os outros elementos. 0 tipo II acontece quando se começa por um ou outro detalhe contíguo ao retângulo ou junto à armação faz os detalhes. No tipo III o sujeito faz um contorno geral da figura, sem diferenciar a armação central, e nesse contorno coloca os detalhes. 0 tipo IV apresenta uma justaposição de detalhes. Existem ainda os tipos V (detalhes sobre fundo confuso), VI (redução a um esquema familiar) e VII (garatuja) (Rey, 2010), não encontrados nesta pesquisa.

0 resultado obtido do tipo de cópia da Figura Complexa de Rey evidencia a diferença entre as escolas $\left(X^{2}=9,15 ; p=0,003\right)$. Na escola particular não se encontrou nenhuma cópia do tipo IV, enquanto na rede pública houve sete ocorrências. Considerase os tipos I, II e III como planejados e os tipos IV, V, VI e VI como não planejados.

Não se esperava o tipo IV de cópia, principalmente em professores, pois é mais característico dos cinco aos dez anos, com maior frequência dos quatro aos sete anos, diminuindo gradativamente até a idade adulta, quando atinge seu mínimo (Rey, 1999). De acordo com o manual do teste, para a faixa etária dos participantes desta pesquisa, esperava-se maior frequência dos tipos I e II, pois caracteriza uma percepção mais completa da figura.
Alves e Brito (2007) afirmam que ao solucionar um problema, inicialmente percebem-se os elementos componentes, analítica e sinteticamente, para então isolá-los e estabelecer hierarquia, combinações e relações entre eles. Esta percepção, segundo as autoras, é formada por um conjunto de processos psicológicos, por meio dos quais as pessoas reconhecem, organizam, sintetizam e fornecem significação cognitiva às sensações recebidas dos órgãos dos sentidos.

Para os professores, o planejamento é fundamental, visto que todos precisam preparar e ordenar os conteúdos a ensinar, fazer a graduação do mais fácil para o mais difícil e organizar-se no tempo, tanto para uma aula, quanto para todo o ano letivo. Este processo envolve, além do planejamento, a memória.

Na inserção e compreensão dos conceitos propriamente ditos, Gazzaniga e Heatherton (2005) entendem a memória como "uma capacidade do sistema nervoso de adquirir e reter habilidades e conhecimentos utilizáveis, permitindo que os organismos se beneficiem da experiência" (p. 216).

Para Davidoff (2001), a memória é o envolvimento de processos e estruturas que trabalham para o armazenamento e recuperação de experiências, e a autora salienta que o sistema de memória passa por três procedimentos, que são a codificação, o armazenamento e a recuperação, e as estruturas são de três tipos: sensorial, curto e longo prazo.

A análise do $t$ de Student indicou uma diferença significativa entre os professores da escola pública e da escola particular na cópia $(\mathrm{t}=2,79 ; \mathrm{gl}=63$; $\mathrm{p}=0,007)$ e na memória da Figura de Rey $(\mathrm{t}=3,23$; $\mathrm{gl}=63 ; \mathrm{p}=0,002)$. Outra diferença significativa foi entre o número de acertos $(t=2,42 ; g l=63 ; p=0,019)$ e o número de erros do teste $\mathrm{AC}(\mathrm{t}=-2,19 ; \mathrm{gl}=63$; $\mathrm{p}=0,032$ ).

A atenção concentrada é a capacidade em manter o foco em um só estímulo, independentemente do tempo, e se relaciona ao freio inibitório. A atenção seletiva amplia o foco, vê o que está acontecendo ao redor e está relacionada ao tálamo. 0 número alto de erros no teste $\mathrm{AC}$ está relacionado à má atenção concentrada, enquanto o alto número de omissões está relacionado à má atenção seletiva (Gazzaniga \& Heatherton, 2005).

Segundo Gazzaniga e Heatherton (2005), atenção é a seleção de quais estímulos sensoriais o cérebro deve descartar e quais deve transmitir para 
níveis superiores de processamento. Acorda então com a conceituação de Davidoff (2001): "A essa abertura seletiva a uma pequena porção de fenômenos sensoriais incidentes chamamos de atenção, que parece estar envolvida em muitas atividades mentais" (p. 143).

\section{Considerações finais}

Obteve-se nesta pesquisa a análise de uma amostra de 65 professores do ensino fundamental de duas escolas de Curitiba. Nesse contexto, perceberam-se diferenças estatísticas entre as escolas. A principal delas encontrou-se no tipo de cópia, pois o tipo IV não deveria ser encontrado em professores, já que sugere falta de planejamento. Porém, na escola pública, a cópia de alguns professores se enquadra neste tipo, enquanto que na escola particular não houve nenhuma ocorrência.

Levantaram-se algumas hipóteses para explicar o fenômeno encontrado: a estrutura física, pois a escola pública não tem as mesmas condições financeiras que a particular; a clientela atendida pelas escolas, pois os alunos da escola particular são diferentes dos da escola pública em vários sentidos, a começar pela classe social; a relação entre o fracasso escolar e a baixa expectativa do professor quanto ao desempenho acadêmico de seus alunos, especialmente quando estes são provenientes de classes sociais mais desfavorecidas; o ambiente e as relações interpessoais, que são diferentes de escola para escola, independente de ser particular ou pública; e o tempo de atuação e a idade dos participantes da pesquisa. Para estas hipóteses serem comprovadas ou refutadas, novas pesquisas precisam ser feitas.

Este estudo não se pretende ser generalista, pois as diferenças entre professores de escolas públicas e particulares não acontecem sempre desta forma. Sabe-se que os resultados aqui obtidos representam apenas o contexto da realidade vivida pelos professores entrevistados. Esta pesquisa representa um recorte de um determinado período de duas escolas, sendo uma particular e uma pública, em Curitiba.

É necessário ressaltar a necessidade de estudos que aprofundem e complementem este tipo de investigação. Amostras maiores e a mensuração de outras funções cognitivas e suas relações podem colaborar para a obtenção de mais conhecimento sobre este público alvo. Dados referentes a contextos específicos, como professores de ensino fundamental são bem-vindos e contribuirão para que o psicólogo da saúde entenda como está este profissional.

\section{Referências}

Alves, E. V. \& Brito, M. R. F. (2007). Relações entre a percepção da estrutura de um problema, a memória e a memória matemática. Temas em Psicologia, 15(2), 207-215.

Cambraia, S. V. (2003). Teste AC. 3a ed. São Paulo: Vetor.

Capovilla, A. G. S. (2006). Desenvolvimento e Validação de instrumentos neuropsicológicos para avaliar funções executivas. Avaliação Psicológica, 5(2), 239-241.

Capovilla, A. G. S., Assef, E. C. dos S., \& Cozza, H. F. P. (2007). Avaliação neuropsicológica das funções executivas e relação com desatenção e hiperatividade. Avaliação Psicológica, 6(1), 51-60.

Davidoff, L. L. (2001). Introdução à Psicologia. 3a ed. São Paulo: Pearson Makron Books.

Eysenck, M. W. \& Keane, M. T. (2007). Manual de Psicologia Cognitiva. 5a ed. Porto Alegre: Artmed.

Gazzaniga, M. S. \& Heatherton, T. F. (2005). Ciência psicológica: mente, cérebro e comportamento. Porto Alegre: Artmed.

Goldberg, E. (2002). O cérebro executivo. Rio de Janeiro: Imago.

Hamdan, A. C., \& Pereira, A. P. de A. Avaliação Neuropsicológica das Funções Executivas: Considerações Metodológicas. (2009) Psicologia: Reflexão e Crítica, 22(3), 386-393.

Izquierdo, I. (2002). Memória. Porto Alegre: Artmed.

Jamus, D. R., \& Mader, M. J. (2005). Figura Complexa de Rey e seu papel na avaliação neuropsicológica. Journal of Epilepsy and Clinical Neurophysiology, 11(4), 193-198.

Luria, A. R. (1991). Curso de Psicologia Geral: atenção e memória. (Vol. 3). 2a ed. Rio de Janeiro: Civilização Brasileira.

Ratey, J. J. (2002). O cérebro: um guia para o usuário. Rio de Janeiro: Objetiva.

Psicol. Argum. 2014 out./dez., 32(79), 91-98 
Rey, A. (1999). Teste de cópia e de reprodução de memória de figuras geométricas complexas. São Paulo: Casa do Psicólogo.

Rueda, F. J. M., \& Castro, N. R. (2010). Capacidade Atencional: há decréscimo com o passar da idade? Psicologia, Ciência e Profissão, 30(3), 572-587.
Sternberg, R. J. (2000). Psicologia cognitiva. Porto Alegre: Artes Médicas Sul. 